\title{
Establishment and characterization of GCSR1, a multi-drug resistant signet ring cell gastric cancer cell line
}

\author{
XIN XU $^{1 *}$, LI-JUAN QIAN ${ }^{2 *}$, XING-YUN SU ${ }^{1}$, KUI-FENG HE ${ }^{1}$, KE-TAO JIN $^{1}$, LIN-HUI GU $^{2}$, \\ JIAN-GUO FENG ${ }^{2}$, GUANG-LIANG LI ${ }^{1}$, QUAN ZHOU ${ }^{1}$, ZHEN-ZHEN XU ${ }^{1}$, \\ HAO-HAO WANG ${ }^{1}$, JING ZHANG ${ }^{1}$, JIANG CAO ${ }^{3}$ and LI-SONG TENG ${ }^{1}$ \\ ${ }^{1}$ Department of Surgical Oncology, The 1st Affiliated Hospital, Zhejiang University School of Medicine, \\ Hangzhou, Zhejiang $310003 ;{ }^{2}$ Zhejiang Cancer Research Institute, Zhejiang Province Cancer Hospital, \\ Zhejiang Cancer Center, Hangzhou, Zhejiang 310022; ${ }^{3}$ Clinical Research Center, The 2nd Affiliated Hospital, \\ Zhejiang University School of Medicine, Hangzhou, Zhejiang 310009, P.R. China
}

Received September 1, 2014; Accepted October 20, 2014

DOI: 10.3892/ijo.2015.2966

\begin{abstract}
Signet ring cell gastric cancer (SRCGC) has very poor prognosis worldwide, and studying its molecular characteristics is urgent for improving the outcome. However, few well-characterized SRCGC cell lines are available for research. Therefore, we established a novel cell line GCSR1, from a Chinese male SRCGC patient. Cell morphology of GCSR1 in culture, maintained in vitro for over 90 passages, is similar to the cells from the patient. GCSR1 cells proliferated in vitro with a doubling time of 67.65 h. Karyotyping showed they were aneuploid. Missense mutation occurred in codon 193 of P53 and deletion occurred in exons 1 and 3 of P16. Results of CCK8 assay revealed that GCSR1 was more resistant to 5-fluorouracil (5-FU) and mitomycin (MMC) than other gastric cancer cell lines. Stem cell marker assay by flow cytometry showed that GCSR1 had high proportion of $\mathrm{CD}_{4} 4^{+}$and/or CD133 ${ }^{+}$cells. It formed colonies easily in soft agar and generated xenograft tumors in nude mice. In conclusion, GCSR1 is a well-established, well-characterized multi-drug resistant cell line with abundant cancer stem cells.
\end{abstract}

Correspondence to: Professor Li-Song Teng, Department of Surgical Oncology, The 1st Affiliated Hospital, Zhejiang University School of Medicine, 79 Qingchun Road, Hangzhou, Zhejiang 310003, P.R. China E-mail: 1steng@zju.edu.cn

Professor Jiang Cao, Clinical Research Center, The 2nd Affiliated Hospital, Zhejiang University School of Medicine, 88 Jiefang Road, Hangzhou, Zhejiang 310009, P.R. China

E-mail: caoj@zju.edu.cn

*Contributed equally

Key words: cell line, drug resistance, establishment, gastric cancer, stem cell, CD44, CD133

\section{Introduction}

Gastric cancer is the second leading cause of death from cancer in the world with low survival and high recurrence especially for the advanced patients (1-3). Signet ring cell gastric cancer (SRCGC) is a histologic diagnosis based on microscopic characteristics as described by the World Health Organization (4). It is reported that the diffuse type gastric cancer, especially the signet ring cell subtype, has become more prevalent and incidence of SRCGC has an abrupt increase of $99.8 \%$ in recent years (5). Moreover, it is more malignant in clinic and has worse prognosis than other forms of gastric cancer (6). Cisplatin (DDP), 5-fluorouracil (5-FU), mitomycin (MMC), and epirubicin (EPI) are the most effective anticancer drugs used in chemotherapy of gastric cancer. However, $>70 \%$ of patients are resistant to these drugs (7) and the mechanism for drug-resistance is not yet fully understood.

The cancer stem cells (CSCs) theory provides new insight into cancer drug-resistance, initiation, development, and metastasis $(8,9)$. A number of studies have shown that CD44positive stem cells play an important role in drug resistance in breast cancer and multiple myeloma $(10,11)$. For gastric cancer, CD44 has been demonstrated to be the most widely used marker for cancer stem cells (12). CD44-positive cells have been demonstrated to exist in many gastric cancer cell lines and show spheroid colony formation ability in vitro and tumorigenic ability in vivo. CD133 is another widely used stem cell marker associated with poor survival in gastric patients (13) and it has not been fully studied in cell lines. Function of stem cells in drug resistance for gastric cancer is not fully understood.

Gastric cancer has been demonstrated to contain CSCs in surface marker assays in many cell lines. Interestingly, the CSC is heterogeneous in different gastric cell lines $(12,14,15)$, and its proportion is low in most of them. Among these cell lines only one of the SRCGC has been studied. Some SRCGC cell lines have been established only in Japan but have not been fully studied (16-18). The study of gastric cancer stem cells has been delayed due to a lack of proper cell line models. 
However, more cell lines are urgently needed because of the heterogeneity in gastric cancer and increasing incidence of SRCGC.

The main purpose of our study was to establish a new SRCGC cell line model for drug resistance and CSCs study. We cultured cells from 6 patients with SRCGC and successfully established one reliable cell line named as GCSR1. Its chemotherapeutic response to most widely used drugs was evaluated and the proportions of CD44 and CD133 were determined. The results show that the cell line was drugresistant and contained abundant cancer stem cells. Thus, the GCSR1 is a useful tool for the drug-resistance and cancer stem cell studies.

\section{Materials and methods}

Patients. The cell line was derived from the malignant primary site from a 57-year-old Chinese male patient with gastric cancer, of which the pathological diagnosis was SRCGC. The patient underwent surgical resection and received FOLFOX6 treatment after the surgery. The study was approved by the Ethics Committee of Zhejiang University, and informed consent was signed by the patient prior to the study.

Establishment of the cell line. Neoplastic tissue was obtained from the primary site of the gastric cancer patient and xenografted into nude mice. When the xenografts reached $\sim 10 \mathrm{~mm}$ in diameter, the tumors were excised to create the cell line GCSR1. Xenografts were minced by sterile blades, and cells were placed in 1640 medium with $20 \%$ fetal bovine serum (FBS). The cells were purified with differential adhesion technique (19). The cells grew well at $37^{\circ} \mathrm{C}$ in a humidified atmosphere containing $5 \% \mathrm{CO}_{2}$ and $95 \%$ air. Without interruption, $>90$ serial passages were successively carried out during a period of $>2$ years. The cells continue to exhibit stable growth.

Cell culture. The human gastric cancer cell lines SGC7901 and KATO-III were kept in our laboratory. SGC7901 was cultured under adherent conditions in RPMI-1640 (Hyclone) with $10 \%$ heat-inactivated fetal bovine serum (FBS, Gibco) at $37^{\circ} \mathrm{C}$ and $5 \% \mathrm{CO}_{2}$. KATO-III was cultured in DMEM (Hyclone) with $10 \%$ heat-inactivated FBS (Gibco) at $37^{\circ} \mathrm{C}$ and $5 \% \mathrm{CO}_{2}$.

Cell proliferation assay. Cells were placed on a 96-well plate (2,000 cells/well) and 42 parallel wells were subjected to the cell proliferation assay for 7 days, 6 wells each. Cell-Counting kit (CCK-8) reagent (BestBio) was added into the well and incubated for $3 \mathrm{~h}$ before reading $(450 \mathrm{~nm})$ using a multiwell spectrophotometer (Bio-Rad).

Karyotyping. G-banding was conducted for karyotyping of GCSR1. GCSR1 cells were cultured in a $37^{\circ} \mathrm{C} \mathrm{CO}_{2}$ incubator and $24 \mathrm{~h}$ later exponentially growing cells were exposed to colcemid $(0.8 \mu \mathrm{g} / \mathrm{ml})$ for $5 \mathrm{~h}$ at $37^{\circ} \mathrm{C}$ for cell cycle arrest at metaphase. Following hypotonic treatment and fixation, the slides were made by dropping cells on glass slides and stained by Giemsa using a routine laboratory procedure.

Soft agar colony formation assay. Cells (500-1,000) were suspended in $0.3 \%$ agarose (0815, Amresco) in RPMI-1640 containing $20 \%$ FBS. This suspension was overlaid onto a solid layer of $0.6 \%$ agarose in a 6-well plate. The cells were treated with fresh RPMI-1640 containing 20\% FBS every other day. Three weeks later, the cells were photographed under a microscope.

Mutation analysis of P53 and P16. Genomic DNA was extracted from GCSR1 using AxyPrep DNA Gel Extraction kit. Polymerase chain reactions (PCR) of P53 exons 5-8 and P16 exons 1 and 3 were performed. PCR products were sequenced (Invitrogen). The oligonucleotide primers were 5-GGA ATT CCT CTT CCT GCA GTA CTC C-3 (forward) and 5-GGA ATT CAG TTG CAA ACC A-3 (reverse) for exons 5 and 6 of P53 (378 bp); 5-GGA ATT CTC CTA GGT TGG CTC TGA C-3 (forward) and 5-GGA ATT CCT GCT TGC TTA CCT CGC T-3 (reverse) for exons 7 and 8 of P53 (590 bp); 5-TCT GCG GAG AGG GGG AGA GCA G-3 (forward) and 5-GCG CTA CCT GAT TCC AAT TC-3 (reverse) for exon 1 of P16 (280 bp); 5-GGA TGT TCC ACA CAT CTT TG-3 (forward) and 5-ATG AAA ACT ACG AAA GCG GG-3 (reverse) for exon 3 of P16 (189 bp). The PCR conditions were: 30 cycles of $30 \mathrm{sec}$ denaturation at $95^{\circ} \mathrm{C}, 30 \mathrm{sec}$ annealing at $55^{\circ} \mathrm{C}$ for $\mathrm{P} 53$ and $58^{\circ} \mathrm{C}$ for $\mathrm{P} 16,40 \mathrm{sec}$ extension at $74^{\circ} \mathrm{C}$, and $10 \mathrm{~min}$ final extension at $72^{\circ} \mathrm{C}$. Subsequently, PCR products were loaded onto gels running for $20 \mathrm{~min}$ at $70 \mathrm{~V}$.

Flow cytometry analysis. Seventy-ninety percent confluent cells in a 100-mm cell plate were dissociated from plates using trypsin-EDTA (Invitrogen), centrifuged, and then stained with CD44 (11-0441, BD Biosciences), isotype control antibody CD44 (11-4031, BD Biosciences) or CD133 (130-080-801, Miltenyi Biotec), isotype control antibody CD133 (130-092-212, Miltenyi Biotec) at $4^{\circ} \mathrm{C}$ for $30 \mathrm{~min}$. Analyses were performed using a BD FACSCanto II (BD Biosciences).

Tumorigenicity in nude mice. To determine the tumorigenicity of the cell lines in vivo, $6 \times 10^{6}$ viable cells were suspended in $200 \mu \mathrm{l}$ PBS and subcutaneously injected into 5 nude mice. The mice were examined every three days.

Chemosensitivity assays. The anticancer drugs, 5-FU (F6627), DDP (P4394), MMC (Y0000378Y) and EPI (E9406) were from Sigma-Aldrich. All drugs were used as recommended by the supplier. Sensitivity of GCSR1 cells to each drug was examined using the CCK- 8 kit (BestBio). Briefly, cells were plated at a density of $2 \times 10^{4}$ cells per well in 96 -well plates containing $100 \mu \mathrm{l}$ of culture medium. After 24-h incubation at $37^{\circ} \mathrm{C}$, drugs were added into wells at a total volume of $10 \mu \mathrm{l}$ per well and incubated for an additional $72 \mathrm{~h}$. CCK-8 reagent was then added into each well and incubated for $3 \mathrm{~h}$ before reading at a wavelength of $450 \mathrm{~nm}$ using a multiwell spectrophotometer (Bio-Rad). $\mathrm{IC}_{50}$ values were calculated using GraphPad Prism 5 (GraphPad software) at least three independent experiments.

Migration and invasion assays. Briefly, $8 \times 10^{5}$ cells were plated on upper chambers of Transwell plates (Corning) and $700 \mu \mathrm{l}$ of RPMI-1640 with 10\% FBS was added to the lower chambers. The plates were then placed in an incubator at $37^{\circ} \mathrm{C}$ with $5 \%$ $\mathrm{CO}_{2}$ for $12 \mathrm{~h}$. 

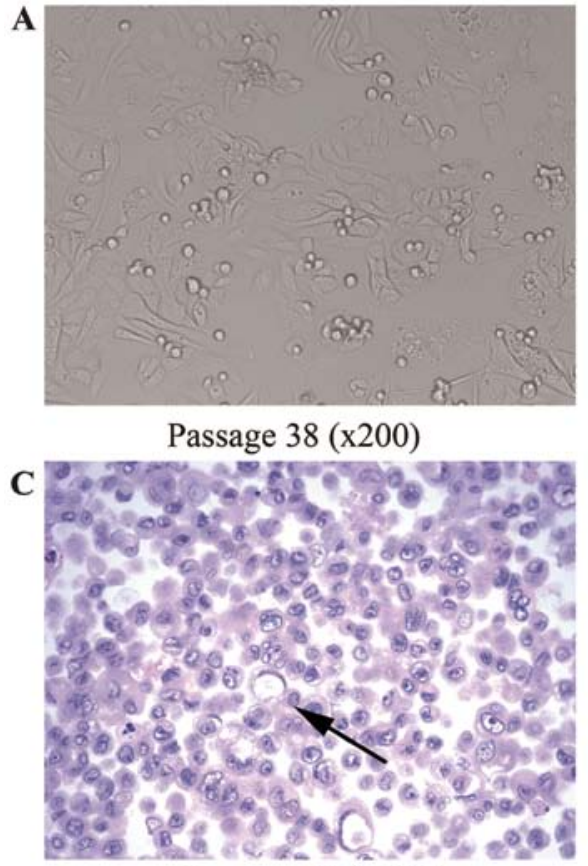

Passage $38(\mathrm{x} 400)$

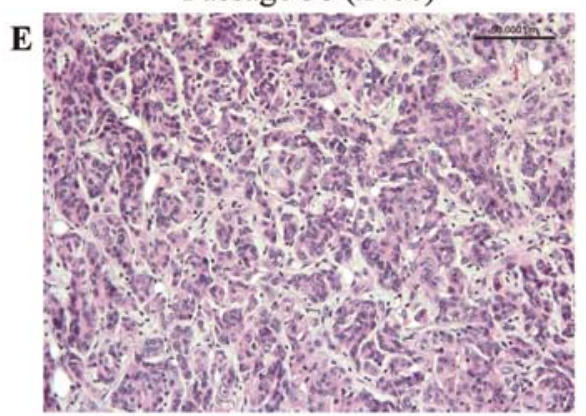

GCSR1 (x200)
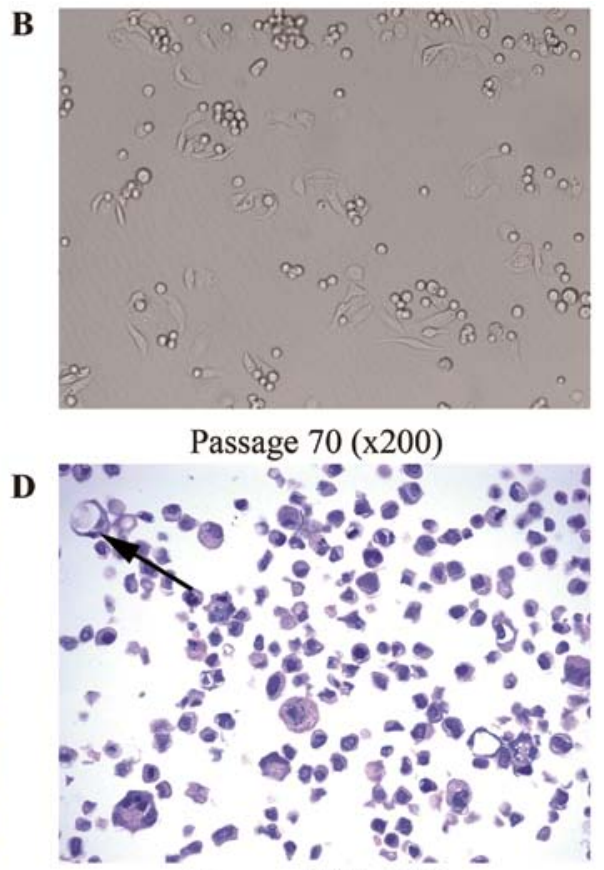

Passage $70(\mathrm{x} 400)$

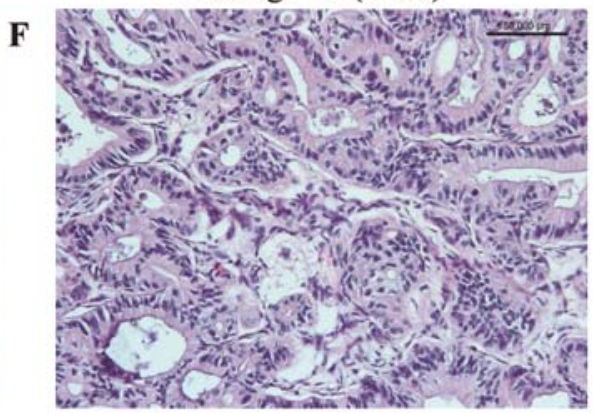

Primary tumor $(\mathrm{x} 200)$

Figure 1. Morphological characteristics of cells from GCSR1. (A and B) Cells were photographed under microscope. Shapes of these cells from passages 38 and 70 were round, polygonal and fusiform. Magnification x200. Scale bar, $50 \mu \mathrm{m}$. (C and D) H\&E staining of the GCSR1 cells from passages 38 and 70 both showed typical signet ring cell morphology (indicated by the arrows). Magnification x400. Scale bar, $20 \mu \mathrm{m}$. H\&E staining of the GCSR1 cell line implantation (E) was similar to the original tumor from the patient biopsy (F). Magnification x200. Scale bar, $50 \mu \mathrm{m}$.

After incubation, the cells remaining in the upper chamber were carefully removed, and the Transwell membranes were fixed with dehydrated ethanol and stained with $0.2 \%$ crystal violet. To count the fixed cells, photographs were taken from 5 independent fields at $\mathrm{x} 200$ magnification. Independent experiments were performed in triplicate.

For the cell invasion assay, Matrigel (356234,BD Biosciences) was thawed on ice at $4^{\circ} \mathrm{C}$ overnight and diluted with serum-free medium at a ratio of 1:9. The Transwell chambers were coated with $40 \mu \mathrm{l}$ of diluted Matrigel in a 24-well plate and incubated at $37^{\circ} \mathrm{C}$ for $2 \mathrm{~h}$ before $1.5 \times 10^{5}$ cells in serum-free RPMI-1640 medium were seeded into the prepared Transwell chambers. Then, $700 \mu \mathrm{l}$ of 1640 with $10 \%$ FBS was added to the lower chambers. The 24 -well plate was incubated at $37^{\circ} \mathrm{C}$ with $5 \%$ $\mathrm{CO}_{2}$ for $12 \mathrm{~h}$. Cells were stained and counted as in the migration assay.

Western blotting. Western blotting was performed with a SDS-PAGE electrophoresis system. Briefly, 20- $\mu$ g protein samples were resuspended in a reduced sample buffer, and then electrophoresed on an 8-10\% Tris gel with Tris running buffer, blotted to PVDF membrane, and sequentially probed with primary antibodies against Her2 (1:200, SC-284, Santa Cruz Biotechnology), EGFR (1:10,000, ab32077, Abcam), E-cad (1:1,000, ab1416, Abcam), vimentin (1:200, Santa Cruz Biotechnology). Secondary antibodies coupled to horseradish peroxidase (HRP) were detected through autoradiography using enhanced chemiluminescence (ECL Plus, Millipore). Glyceraldehyde-3-phosphate dehydrogenase (GAPDH) $(1: 5,000)$ (KC-5G4, Kangchen) was used as a loading control.

Statistical analysis. The unpaired 2-tailed t-test was used with GraphPad Prism 5. P $<0.01$ was considered statistically significant.

\section{Results}

Morphological features. The culture cells from passages 38 and 70 were analyzed by a microscope and H\&E staining for the morphological feature to confirm that the cell line was signet ring cell origin and stable in vitro. GCSR1 presented various shapes under the microscope at passage 38 (Fig. 1A) 
A

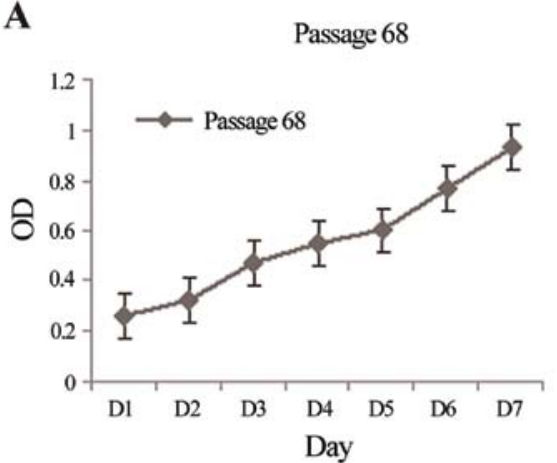

B

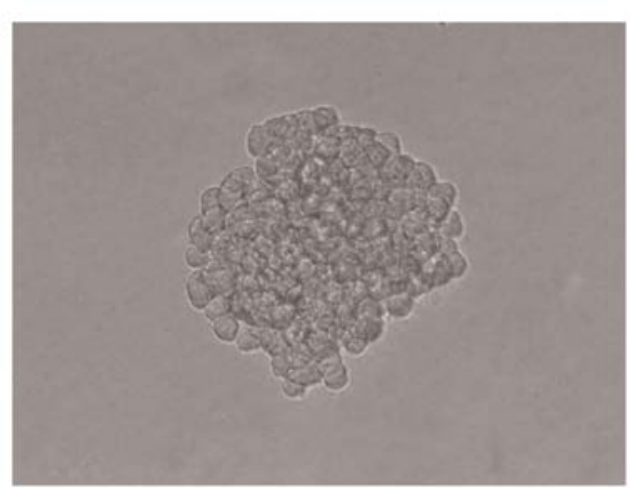

\begin{tabular}{|c|c|c|}
\hline Plate & $\begin{array}{c}\text { Number of } \\
\text { clonies }\end{array}$ & $\begin{array}{c}\text { Cloning } \\
\text { efficiency } \\
(\%)\end{array}$ \\
\hline Plate 1 & 54 & 10.8 \\
\hline Plate 2 & 51 & 10.2 \\
\hline Plate 3 & 54 & 10.8 \\
\hline
\end{tabular}

Figure 2. Proliferation of GCSR1 cells. (A) Growth curve of GCSR1 was measured by CCK8 at passage 68. Doubling time was $67.65 \mathrm{~h}$. (B) Colony formation assay in soft agar. Magnification x 200. Scale bar, $50 \mu \mathrm{m}$. (C) The average cloning efficiency is $10.6 \%$ performed in three assays.

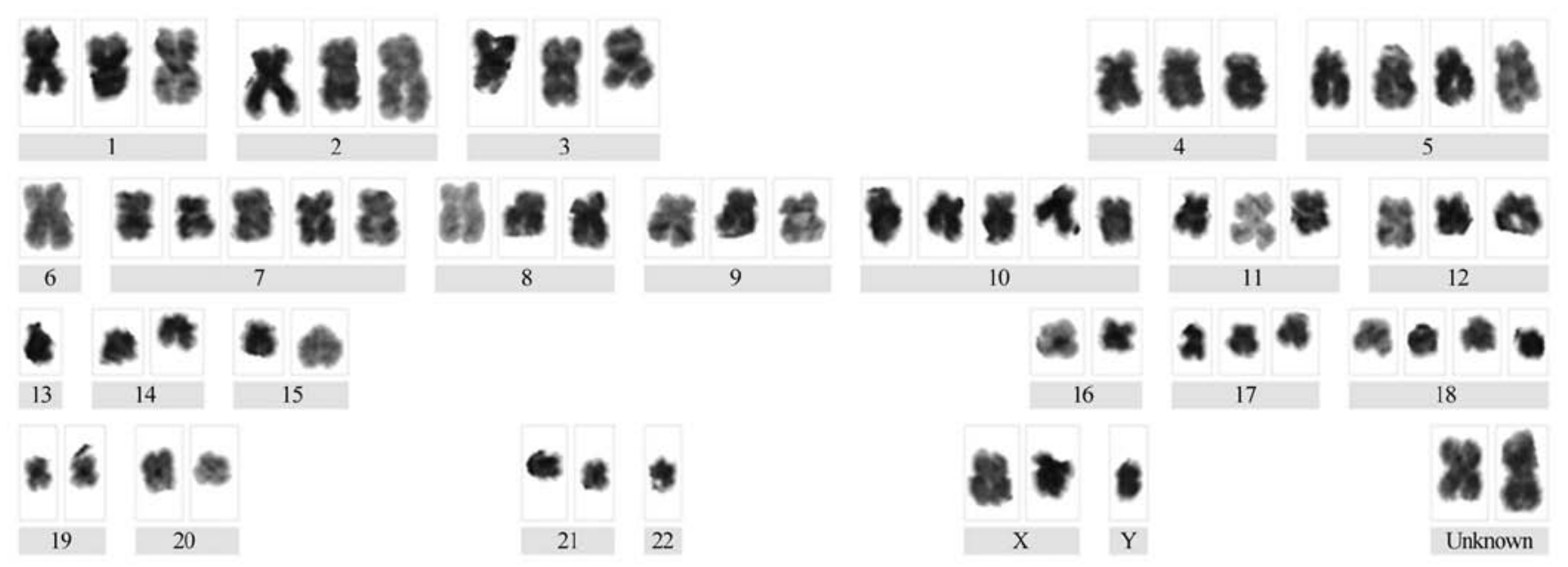

Figure 3. Cytogenetic analysis of the GCSR1 cell line. Karyotype of GCSR1 exhibited aneuploid with 65 chromosomes.

and the morphology was similar with passage 70 (Fig. 1B). H\&E staining of cells at passages 38 (Fig. 1C) and 70 (Fig. 1D) both showed typical signet ring cell morphology, in which the cells were filled with mucin vacuoles that pushed the nucleus to one side. Further, the cell culture implantation and primary tumor from animals were analyzed by H\&E staining to confirm the cell line was pathologically identical to primary tumor, which showed that GCSR1 cells (Fig. 1E) were similar to the primary tumor in vivo (Fig. 1F).

Proliferation features. The GCSR1 cells remained in culture for $>90$ passages and became a stable cell line. It proliferated with a doubling time of approximately $67.65 \mathrm{~h}$ (Fig. 2A) in normal culture and demonstrated anchorage-independence and is able to form colonies in soft agar (Fig. 2B and C).
Karyotype analysis. Karyotype analysis showed that GCSR1 cells were aneuploid with a median chromosome number 65 (XXY). There were multiple copies of chromosomes A1-A3, B4, B5, C7-C12, E17 and E18; deletions of C6, D13 and G22; and some unknown chromosomes in GCSR1 (Fig. 3).

Sequencing analysis of P53 and P16 mutations. Mutation analysis was performed in GCSR1 cells for the tumor suppressor genes, P53 and P16, respectively. P53 gene exhibited CAT $\rightarrow$ CGT missense mutation (histidine $\rightarrow$ arginine) in codon 193 of exon 6 (Fig. 4A), while no other mutations in exon 5 or exons 7 and 8 were found (data not shown). Homozygous loss of codons 1 and 3 was observed in P16 (Fig. 4B). 

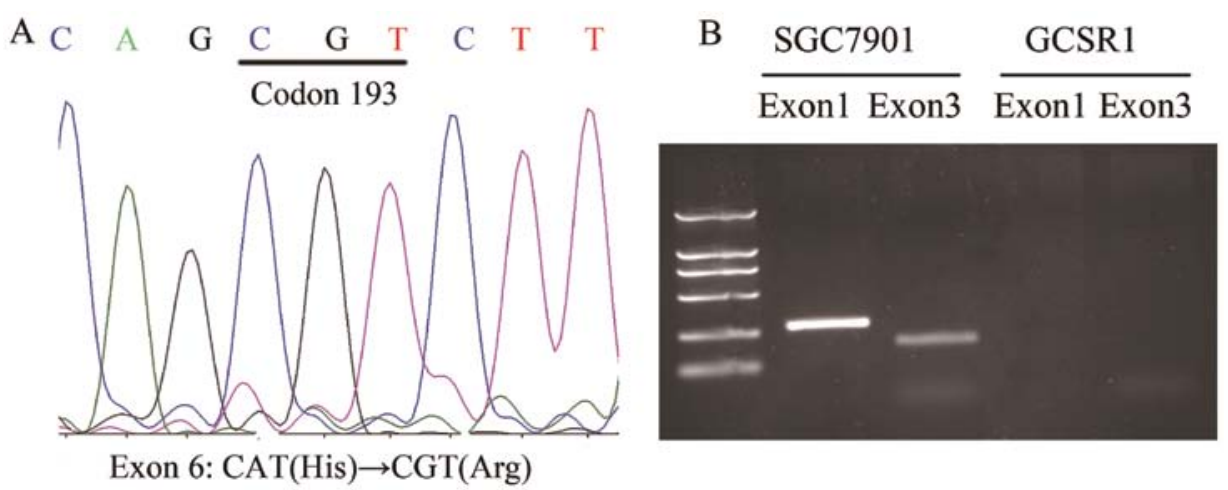

Figure 4. Sequencing analysis of p53 and p16 genes. (A) PCR-SSCP analysis of p53 exon 6. Nucleotide sequence of p53 indicates codon 193 missense mutation $(\mathrm{CAT} \rightarrow \mathrm{CGT})$. (B) PCR analysis of p16 exons 1 and 3 . The result indicates homozygous p16 missing of exons 1 and 3 in GCSR1.
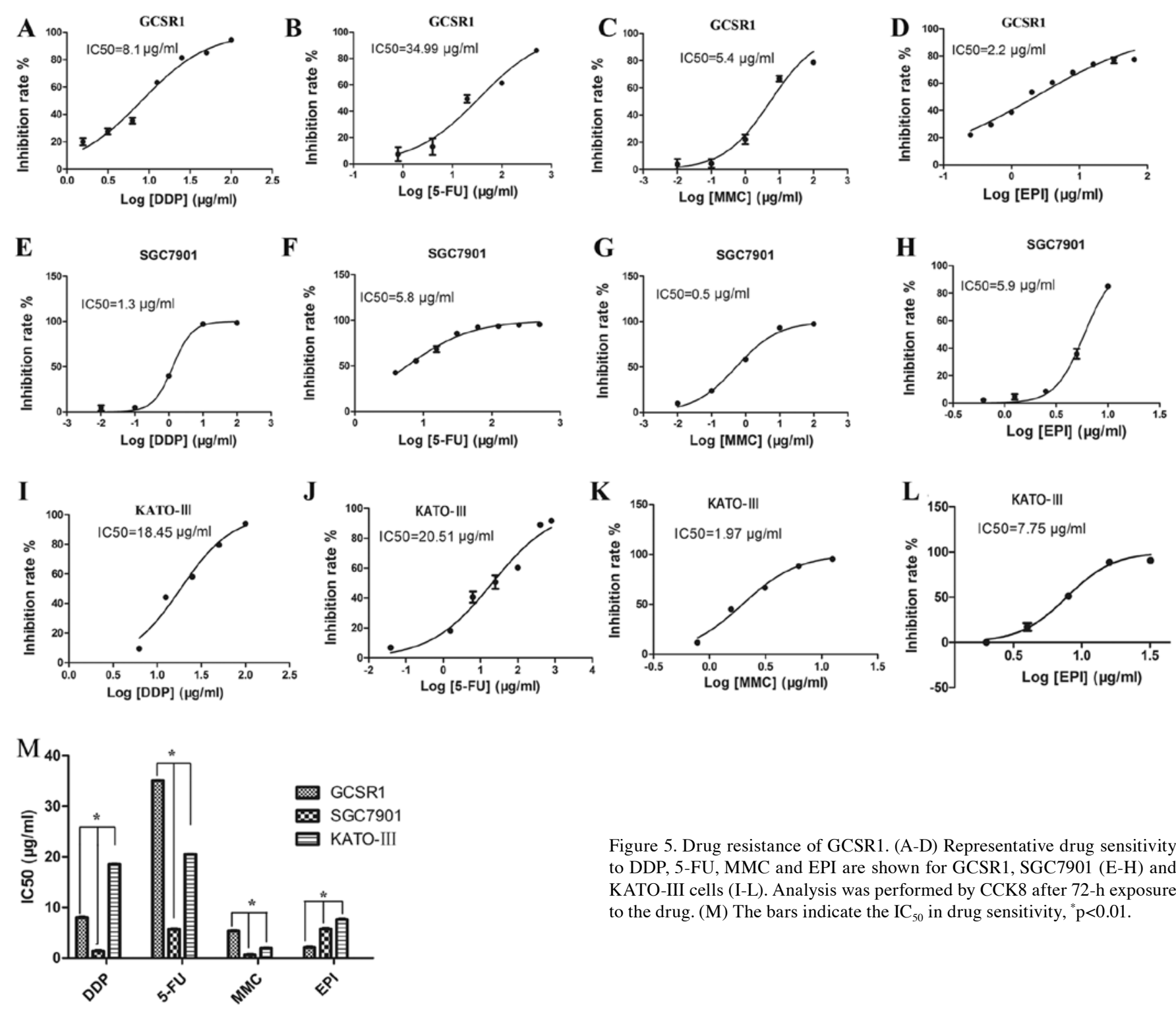

Drug sensitivity assay. To clarify the drug sensitivity of GCSR1 cells, DDP, 5-FU, MMC and EPI were examined. The SGC7901 (20) (intestinal gastric cancer) and KATO-III (16) (signet ring cell gastric cancer) cell lines were used as positive control. The $\mathrm{IC}_{50}$ of GCSR1 to DDP, 5-FU, MMC, and EPI were

Figure 5. Drug resistance of GCSR1. (A-D) Representative drug sensitivity to DDP, 5-FU, MMC and EPI are shown for GCSR1, SGC7901 (E-H) and KATO-III cells (I-L). Analysis was performed by CCK8 after 72-h exposure to the drug. (M) The bars indicate the $\mathrm{IC}_{50}$ in drug sensitivity, ${ }^{*} \mathrm{p}<0.01$.

8.1, 34.99, 5.4 and $2.2 \mu \mathrm{g} / \mathrm{ml}$, respectively, after 72-h exposure (Fig. 5A-D). The $\mathrm{IC}_{50}$ of SGC7901 to DDP, 5-FU, MMC, and EPI were $1.3,5.8,0.5$ and $5.9 \mu \mathrm{g} / \mathrm{ml}$, respectively (Fig. 5E-H). The $\mathrm{IC}_{50}$ of KATO-III cells to DDP, 5-FU, MMC and EPI were 18.45, 20.51, 1.97 and $7.75 \mu \mathrm{g} / \mathrm{ml}$, respectively (Fig. 5I-L). 

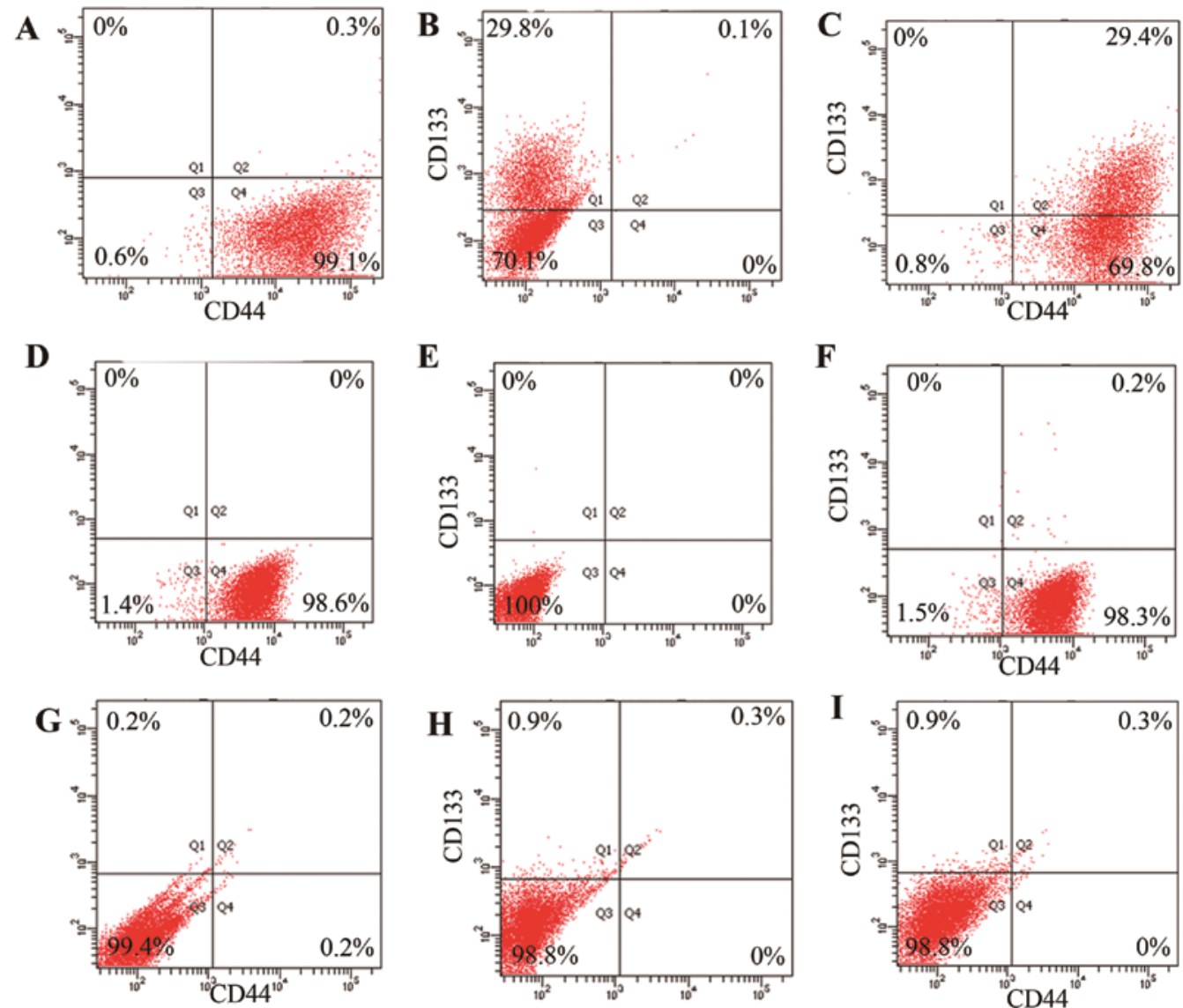

Figure 6. Expression of CD44 and/or CD133. (A and B) 99.1\% cells were CD44-positive and 29.8\% were CD133-positive in GCSR1 analyzed by flow cytometry. (C) Nearly all CD133-positive cells were CD44-positive. (D and E) 98.6\% cells were CD44-positive and 0\% were CD133-positive in SGC7901 cells. (F) However, CD44(+)CD133(+) SGC7901 cells were only $0.2 \%$ positive. (G, H and I) In cell line KATO-III, only $0.2 \%$ of cells were CD44-positive, $0.9 \%$ cells were CD133-positive and only $0.3 \%$ cells were CD44(+)CD133(+).

$\mathbf{A}$
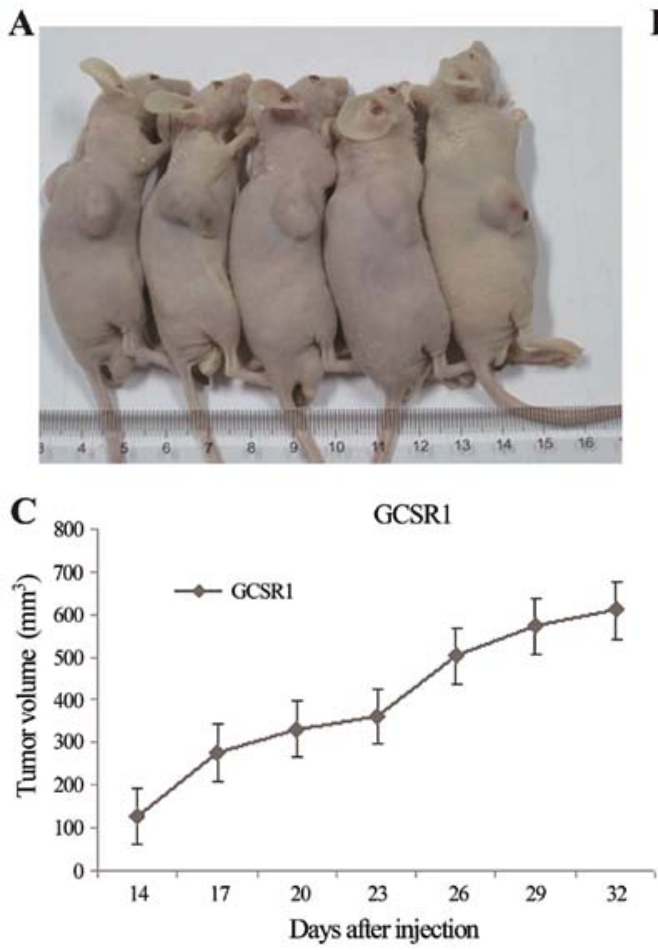

B

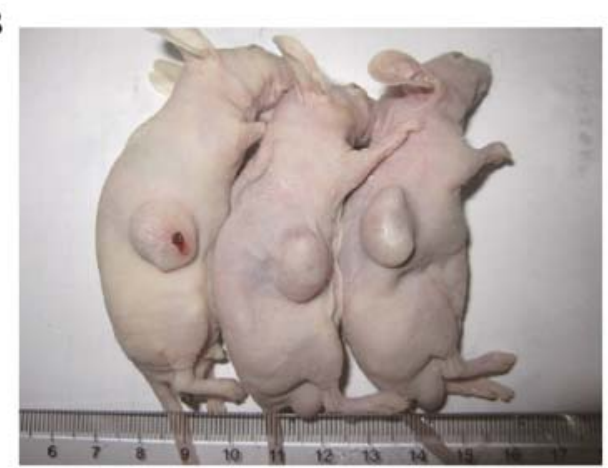

D

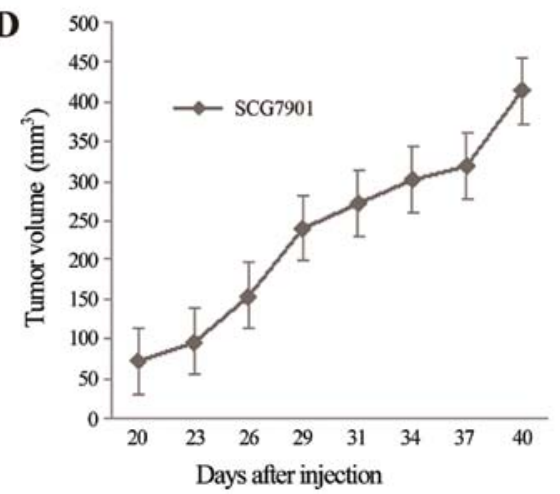

Figure 7. Self-renewal ability in vivo. (A and B) Appearance of a subcutaneous GCSR1 and SGC7901 tumors in five nude mice. The GCSR1 cells formed tumors in 100\% of mice (5 of 5 mice) but SGC7901 cells only formed tumor in 60\% mice. (C and D) Tumor growth curve of GCSR1 cells and SGC7901 cells after subcutaneous injection. 

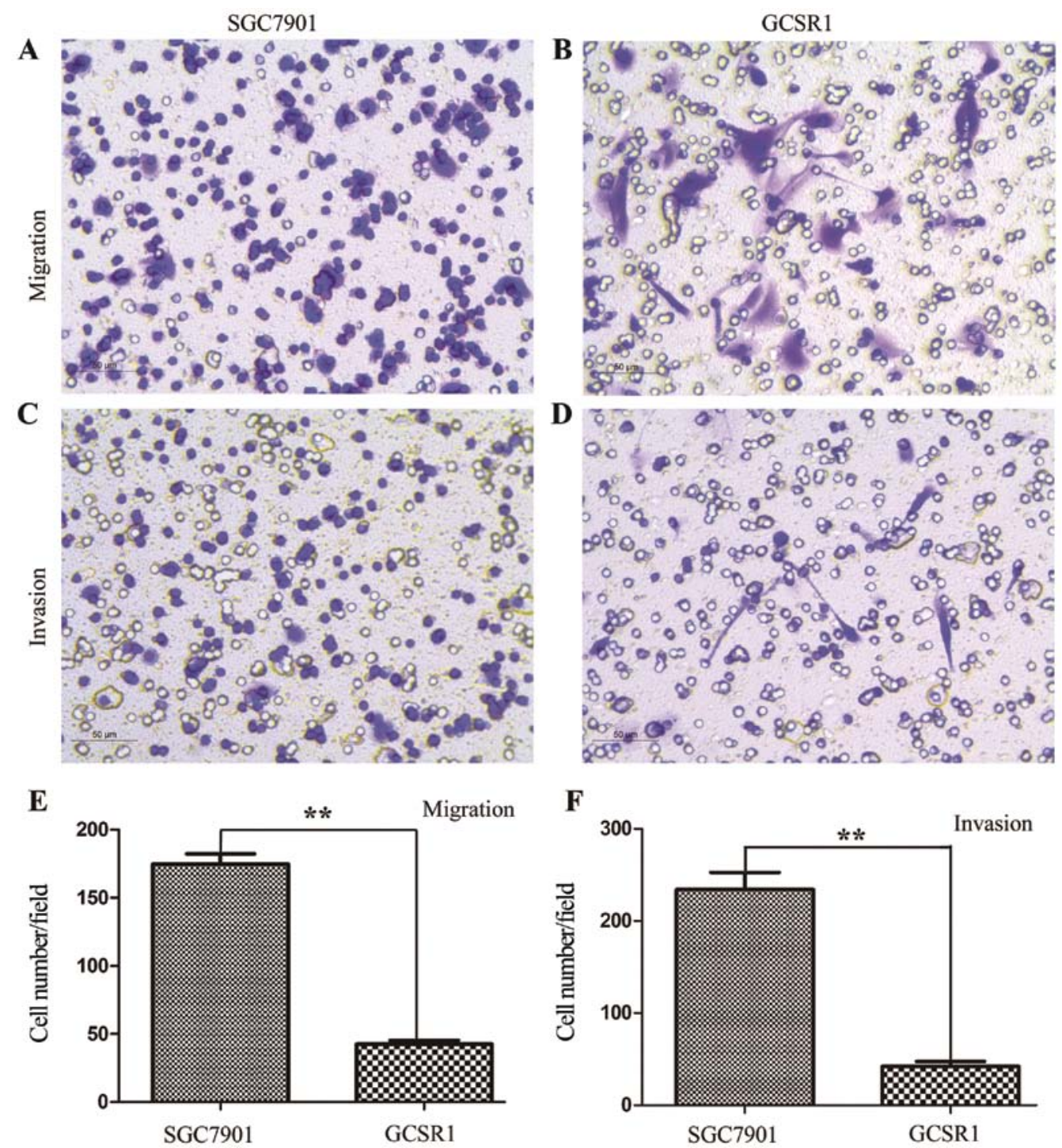

Figure 8. Transwell assay was used to evaluate the effects of GCSR1 and SGC7901 on cell migration and invasion. (A and B) Transwell assay was used to evaluate migration ability in SGC7901 and GCSR1. (C and D) Transwell assay was used to evaluate invasion ability in SGC790 and GCSR1. The magnification was $\mathrm{x} 200$. Scale bar, $50 \mu \mathrm{m}$. (E and F) Comparison of SGC7901 and GCSR1 in mean migration and invasion effects. ${ }^{* *} \mathrm{P}<0.01$.

GCSR1 cells were more resistant than the SGC7901 cells to three drugs: 6.20-fold for DDP, 6.0-fold for 5-FU and 10.8-fold for MMC (Fig. 5M); and more resistant than the KATO-III cells to two drugs: 1.7-fold for 5-FU and 2.74-fold for MMC (Fig. 5M). These results indicate that GCSR1 is a multi-drug resistant cell line.

CD44 and CD133 expression assay. Flow cytrometry was performed to clarify the proportion of CSCs that was high in GCSR1, the results showed that $99.2 \%$ of GCSR1 cells were CD44-positive (Fig. 6A) and $29.5 \%$ were CD133-positive (Fig. 6B). Interestingly, almost all the CD133-positive cells were also CD44-positive (Fig. 6C). By contrast, $98.6 \%$ of SGC7901 cells were CD44-positive (Fig. 6D) and 0\% were CD133-positive (Fig. 6E) and $0.2 \%$ were $\mathrm{CD} 44^{+} \mathrm{CD} 133^{+}$ (Fig. 6F). In the cell line KATO-III, only $0.2 \%$ of the cells were CD44-positive (Fig. 6G), 0.9\% were CD133-positive (Fig. 6H), and $0.3 \%$ were $\mathrm{CD} 44^{+} \mathrm{CD} 133^{+}$(Fig. 6I). These results show that high proportion of stem cells partially explained the drug resistance in GCSR1 cells.
Tumorigenicity in vivo. In order to confirm that the GCSR 1 cells have higher proportion of stem cells, we examined self-renewal ability in vivo, which is the most important characteristic of CSCs (21). Viable cells $\left(6 \times 10^{6}\right)$ were implanted by s.c. injection into 5 nude mice. The GCSR1 cells demonstrated a significant tumor growth, with $100 \%$ tumor formation rate (Fig. 7A), while only 60\% was seen in SGC7901 (Fig. 7B) and 0\% in KATO-III (data not shown). Tumor volumes in GCSR1 (Fig. 7C) were larger than SGC7901 (Fig. 7D) and KATO-III (data not shown). These data indicate that GCSR1 had abundant stem cells.

Migration and invasion assay. In vitro transwell migration and invasion assays were used to examine the migratory and invasive potential of the GCSR 1 cells. GCSR 1 showed both migration and invasion after $12 \mathrm{~h}$, which were weaker than those in SGC7901 (Fig. 8), while KATO-III showed no migration or invasion (data not shown).

Western blots of HER2, EGFR and EMT markers. HER pathway played a critical role in stem cell survival (22) and 


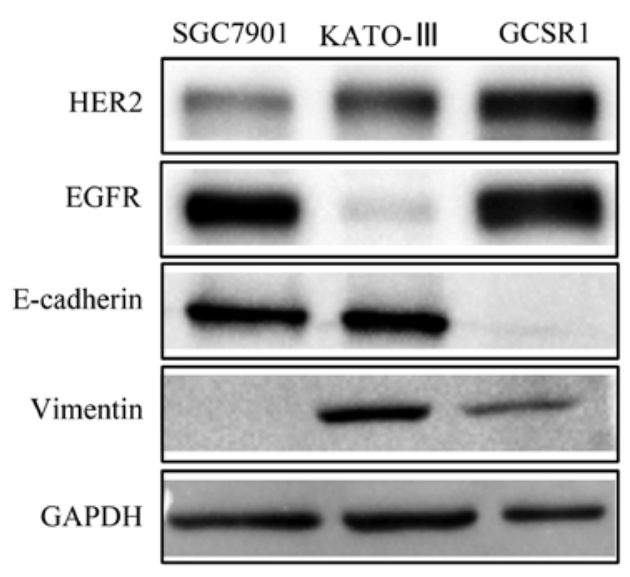

Figure 9. Protein levels of HER2, EGFR, E-cadherin and vimentin in SGC7901, KATO-III and GCSR1 cell lines.

trastuzumab has been proved to target HER2 effectively in advanced gastric cancer (23). EMT markers were reported to be associated with drug resistance and stem cell phonotype (24-28). The expression of these proteins is important for understanding drug resistance and finding potential drug target markers for drug resistant cell line GCSR1. Western blot analyses revealed high expression of HER2 and EGFR in GCSR1, compared with SGC7901 and KATO-III as positive control (Fig. 9). These results demonstrate that HER2 and EGFR can be potential therapy targets in GCSR1. Western blot analyses also revealed that GCSR1 had acquired the expression of fibroblastic-related protein such as vimentin and lost the expression of epithelial specific gene E-cad (Fig. 9), indicating that GCSR1 was transformed to myofibroblast-like cells via epithelial-mesenchymal transition.

\section{Discussion}

Chemotherapy is a major treatment strategy for gastric cancer, but its efficacy is poor. The main reason for drug failure is multidrug resistance (MDR), of which the mechanisms in gastric cancer are complex and have not been clarified. A number of studies have been conducted to reveal the cellular mechanisms of drug resistance in gastric cancer. The most widely used experimental models are the acquired drug-resistant cell lines, which were selected in the presence of cytotoxic agents. By comparing the naive parental cells to these drug-resistant cell lines using cellular and molecular biology tools, many drug-resistance associated molecules have been revealed (29). The classical drugresistant molecules are P-glycoprotein/ABCB1 and MRP1/ $\mathrm{ABCC} 1$, which played important roles in mediating MDR in some gastric cancers (30). However, the drug resistance is complex in clinic and has not been fully solved. New experimental models, especially primary drug resistance cell lines established from clinical samples is required for drug resistance study. GCSR1, which is a new cell line established from a SRCGC patient, showed stronger multi-drug resistance to chemotherapies compared to other cell lines such as SGC7901 and KATO-III. Our results show that GCSR1 holds high homogeneity to the original tumor tissues, so it can represent not only the primary tumor, but also the primary drug resistant model, better than some other established cell lines. It is a useful model for investigation of the mechanisms of gastric cancer drug resistance.

Cancer stem cells have been studied in SGC7901 and KATO-III $(12,15)$, and the results show that these two cell lines contained $\mathrm{CD} 44^{+}$cells but showed weak tumorigenicity in vivo. By contrast, GCSR1 had higher proportions of CD44 stem cells (99.8\%) and showed self-renewal ability both in vitro and in vivo. High proportion of stem cells partially explains the malignancy and drug resistance in GCSR1. Our laboratory has also established a patient-derived human tumor tissue (PDTT) model (31), which is derived from the same patient as the GCSR1 cells. Therefore, further study will need to test the GCSR1 cell line together with the stable PDTT model to confirm the stem cell function in drug resistance.

Targeting therapies have become more attractive as therapeutic strategies in gastric cancer and HER2 is of particular interest as a drug target especially for advanced gastric cancer (23). We tested HER2 expression in GCSR 1 and found it was highly expressed compared with that in SGC7901 and KATO-III. The results indicate that trastuzumab, a monoclonal antibody that interferes with the HER2 receptor, may be considered for the treatment of GCSR1.

Recently, intra-tumor heterogeneity has been clarified for cancer treatment, which was a topic in AACR Annual Meeting 2014. Thus, an in vitro model that can mimic the situation of intratumor heterogeneity is urgently needed. However, long-term cell lines in vitro lead to the selection of subpopulations over time. On the contrary, primary cell lines keep the heterogeneity of the primary tumor and thus provide a useful tool for further study. Moreover, we also established further nine sub-clones from the early passage cells from the same tumor tissue along with GCSR1. These sub-clones display significant heterogeneity in many aspects. We are now conducting more experiments to further study intra tumor heterogeneity of SRCGC. In conclusion, GCSR1 is a well-established, well-characterized multi-drug resistant cell line with abundant cancer stem cells.

\section{Acknowledgements}

This study was supported by the funds from National Natural Science Foundation of China (no. 81272676); National Science and Technology Major Project of the Ministry of Science and Technology of China (no. 2013ZX09506015); Medical Science and Technology Project of Zhejiang Province (no. 2011ZDA009). The authors would like to thank Qin-Yuan Lou, Chi-Hong Zhu and Yu-Tian Ling for their assistance during this study.

\section{References}

1. Jemal A, Center MM, DeSantis C and Ward EM: Global patterns of cancer incidence and mortality rates and trends. Cancer Epidemiol Biomarkers Prev 19: 1893-1907, 2010.

2. Cunningham D, Allum WH, Stenning SP, Thompson JN, van de Velde CJ, Nicolson M, Scarffe JH, Lofts FJ, Falk SJ, Iveson TJ, et al: Perioperative chemotherapy versus surgery alone for resectable gastroesophageal cancer. N Engl J Med 355: 11-20, 2006.

3. Macdonald JS, Smalley SR, Benedetti J, Hundahl SA, Estes NC, Stemmermann GN, Haller DG, A jani JA, Gunderson LL, Jessup JM, et al: Chemoradiotherapy after surgery compared with surgery alone for adenocarcinoma of the stomach or gastroesophageal junction. N Engl J Med 345: 725-730, 2001. 
4. Jass JR, Sobin LH and Watanabe $\mathrm{H}$ : The World Health Organization's histologic classification of gastrointestinal tumors A commentary on the second edition. Cancer 66: 2162-2167, 1990.

5. Henson DE, Dittus C, Younes M, Nguyen H and AlboresSaavedra J: Differential trends in the intestinal and diffuse types of gastric carcinoma in the United States, 1973-2000: increase in the signet ring cell type. Arch Pathol Lab Med 128: 765-770, 2004

6. Taghavi S, Jayarajan SN, Davey A and Willis AI: Prognostic significance of signet ring gastric cancer. J Clin Oncol 30: 3493-3498, 2012.

7. Shah MA and Kelsen DP: Gastric cancer: a primer on the epidemiology and biology of the disease and an overview of the medical management of advanced disease. J Natl Compr Cancer Netw 8: 437-447, 2010

8. Gilbert CA and Ross AH: Cancer stem cells: cell culture, markers, and targets for new therapies. J Cell Biochem 108: 1031-1038, 2009.

9. Passegue E, Rafii S and Herlyn M: Cancer stem cells are everywhere. Nat Med 15: 23, 2009.

10. Palyi-Krekk Z, Barok M, Isola J, Tammi M, Szollosi J and Nagy P: Hyaluronan-induced masking of ErbB2 and CD44enhanced trastuzumab internalisation in trastuzumab resistant breast cancer. Eur J Cancer 43: 2423-2433, 2007.

11. Bjorklund CC, Baladandayuthapani V, Lin HY, Jones RJ, Kuiatse I, Wang H, Yang J, Shah JJ, Thomas SK, Wang M, et al: Evidence of a role for CD44 and cell adhesion in mediating resistance to lenalidomide in multiple myeloma: therapeutic implications Leukemia 28: 373-383, 2014.

12. Takaishi S, Okumura T, Tu S, Wang SS, Shibata W, Vigneshwaran R, Gordon SA, Shimada Y and Wang TC: Identification of gastric cancer stem cells using the cell surface marker CD44. Stem Cells 27: 1006-1020, 2009.

13. Chen S, Hou JH, Feng XY, Zhang XS, Zhou ZW, Yun JP, Chen YB and Cai MY: Clinicopathologic significance of putative stem cell marker, CD44 and CD133, in human gastric carcinoma. J Surg Oncol 107: 799-806, 2013.

14. She JJ, Zhang PG, Wang X, Che XM and Wang ZM: Side population cells isolated from KATO III human gastric cancer cell line have cancer stem cell-like characteristics. World J Gastroenterol 18: 4610-4617, 2012.

15. Xue Z, Yan H, Li J, Liang S, Cai X, Chen X, Wu Q, Gao L, Wu K Nie Y, et al: Identification of cancer stem cells in vincristine preconditioned SGC7901 gastric cancer cell line. J Cell Biochem 113: 302-312, 2012.

16. Yanagihara K, Seyama T, Tsumuraya M, Kamada $\mathrm{N}$ and Yokoro K: Establishment and characterization of human signet ring cell gastric carcinoma cell lines with amplification of the c-myc oncogene. Cancer Res 51: 381-386, 1991.

17. Murakami $\mathrm{H}$, Nakanishi $\mathrm{H}$, Tanaka $\mathrm{H}$, Ito $\mathrm{S}$, Misawa $\mathrm{K}$, Ito $\mathrm{Y}$, Ikehara Y, Kondo E and Kodera Y: Establishment and characterization of novel gastric signet-ring cell and non signet-ring cell poorly differentiated adenocarcinoma cell lines with low and high malignant potential. Gastric Cancer 16: 74-83, 2013.
18. Sekiguchi M, Sakakibara K and Fujii G: Establishment of cultured cell lines derived from a human gastric carcinoma. Jpn J Exp Med 48: 61-68, 1978

19. Kreider BQ, Messing A, Doan H, Kim SU, Lisak RP and Pleasure DE: Enrichment of Schwann cell cultures from neonatal rat sciatic nerve by differential adhesion. Brain Res 207: 433-444, 1981.

20. Lin CH, Fu ZM, Liu YL, Yang JL, Xu JF, Chen QS and Chen HM: Investigation of SGC-7901 cell line established from human gastric carcinoma cells. Chin Med J (Engl) 97: 831-834, 1984.

21. Kreso A and Dick JE: Evolution of the cancer stem cell model. Cell Stem Cell 14: 275-291, 2014.

22. Ithimakin S, Day KC, Malik F, Zen Q, Dawsey SJ, BersanoBegey TF, Quraishi AA, Ignatoski KW, Daignault S, Davis A, et al: HER2 drives luminal breast cancer stem cells in the absence of HER2 amplification: implications for efficacy of adjuvant trastuzumab. Cancer Res 73: 1635-1646, 2013.

23. Bang YJ, Van Cutsem E, Feyereislova A, Chung HC, Shen L, Sawaki A, Lordick F, Ohtsu A, Omuro Y, Satoh T, et al: Trastuzumab in combination with chemotherapy versus chemotherapy alone for treatment of HER2-positive advanced gastric or gastro-oesophageal junction cancer (ToGA): a phase 3, open-label, randomised controlled trial. Lancet 376: 687-697, 2010.

24. Iseri OD, Kars MD, Arpaci F, Atalay C, Pak I and Gunduz U: Drug resistant MCF-7 cells exhibit epithelial-mesenchymal transition gene expression pattern. Biomed Pharmacother 65: 40-45, 2011.

25. McConkey DJ, Choi W, Marquis L, Martin F, Williams MB, Shah J, Svatek R, Das A, Adam L, Kamat A, et al: Role of epithelial-tomesenchymal transition (EMT) in drug sensitivity and metastasis in bladder cancer. Cancer Metastasis Rev 28: 335-344, 2009.

26. Shah AN, Summy JM,Zhang J, Park SI, Parikh NU and Gallick GE: Development and characterization of gemcitabine-resistant pancreatic tumor cells. Ann Surg Oncol 14: 3629-3637, 2007.

27. Wang Z, Li Y, Kong D, Banerjee S, Ahmad A, Azmi AS, Ali S, Abbruzzese JL, Gallick GE and Sarkar FH: Acquisition of epithelial-mesenchymal transition phenotype of gemcitabineresistant pancreatic cancer cells is linked with activation of the notch signaling pathway. Cancer Res 69: 2400-2407, 2009.

28. Mani SA, Guo W, Liao MJ, Eaton EN, Ayyanan A, Zhou AY, Brooks M, Reinhard F, Zhang CC, Shipitsin M, et al: The epithelial-mesenchymal transition generates cells with properties of stem cells. Cell 133: 704-715, 2008

29. Zhao Y, You H, Liu F, An H, Shi Y, Yu Q and Fan D: Differentially expressed gene profiles between multidrug resistant gastric adenocarcinoma cells and their parental cells. Cancer Lett 185: 211-218, 2002.

30. Szakacs G, Paterson JK, Ludwig JA, Booth-Genthe C and Gottesman MM: Targeting multidrug resistance in cancer. Nat Rev Drug Discov 5: 219-234, 2006.

31. Jin K, He K, Han N, Li G, Wang H, Xu Z, Jiang H, Zhang J and Teng L: Establishment of a PDTT xenograft model of gastric carcinoma and its application in personalized therapeutic regimen selection. Hepatogastroenterology 58: 1814-1822, 2011. 